\title{
Adrenergic and cholinergic systems and tonic immobility in chickens
}

\author{
RICHARD W. THOMPSON and DAN JENSEN \\ Western Washington University, Bellingham, Washington 98225
}

\begin{abstract}
To investigate the possible interaction of adrenergic and cholinergic systems in the mediation of tonic immobility (TI) in chickens, 40 cockerel chicks were divided into two groups that received $.5 \mathrm{mg} / \mathrm{kg}$ or $1.0 \mathrm{mg} / \mathrm{kg}$ of epinephrine. Half of each of these groups were given $1.0 \mathrm{mg} / \mathrm{kg}$ or $2.5 \mathrm{mg} / \mathrm{kg}$ of scopolamine prior to testing for TI duration. Results indicated that the highest dose of epinephrine significantly increased TI duration. Although the highest dose of scopolamine attenuated the duration of TI at both epinephrine levels, the effect was not significant.
\end{abstract}

Tonic immobility (TI) has been observed in a wide variety of species and is characterized by profound behavioral inhibition, increased tonicity of muscles, and changes in autonomic function. The response, which is typically brought about by restraining the animal for a brief period, has been hypothesized to be a result of intense fear (Gallup, 1974).

A number of studies have shown that animals injected with epinephrine or norepinephrine prior to testing for TI show increased durations of the response (Braud \& Ginsburg, 1973; Thompson \& Joseph, 1978; Thompson, Scuderi, \& Boren, 1977). Carlton (1969) has suggested that animals faced with stress with which they cannot cope initially show an adrenergic response, which in turn activates a system of neurons that release acetylcholine at their terminal endings. These cholinergic systems are thought to mediate behavioral inhibition, such as freezing. For example, Manto (1967) has demonstrated that rats injected with epinephrine show decreased activity, but rats injected with both epinephrine and scopolamine (a cholinergic blocking drug) show normal activity levels. Recently, Gagliardi and Thompson (1977) and Thompson (1977) have shown that blocking cholinergic systems will reduce TI duration, while enhancing cholinergic activity will prolong the response.

On the basis of Carlton's (1969) hypothesis and the results of Manto's (1967) experiment, one would expect that the increased durations of TI produced by epinephrine could be attenuated by blocking the cholinergic system. The present experiment investigated that hypothesis.

\section{METHOD}

\section{Subjects}

Forty White Leghorn cockerel chicks were obtained from a local hatchery at 1 day of age. The birds were maintained in a commercial brooder with ad-lib food and water and a 12-h lightdark cycle.

\section{Apparatus}

The birds were habituated and tested for TI in unpainted plywood boxes $28 \mathrm{~cm}$ square $\times 43 \mathrm{~cm}$ high. The top of each box was open and the floor was covered with a foam rubber pad $1 \mathrm{~cm}$ thick. The front of each box was covered with black cloth to reduce the bird's view of the experimenter. The cloth was split down the middle to afford ready access to the interior of the box.

\section{Procedure}

On the 5 th posthatch day and continuing for 5 consecutive days, the birds were given three TI habituation trials per day. Habituation consisted in removing the bird from the brooder, placing it in a holding box, and carrying it to the test room. The bird was removed from the holding box and placed in the test chamber from above. The experimenter immediately reached through the curtain in the front of the box, grasped the bird, gently turned it on its side, and held it down for $15 \mathrm{sec}$. If the bird had not spontaneously righted itself after 30-45 sec, it was gently prodded until it stood up. The bird was then removed from the test chamber and placed in the holding box for a 60 -sec intertrial interval. If a bird failed to show TI, it was immediately removed from the test chamber and placed in the holding box.

On the 10th posthatch day, birds were haphazardly selected from the brooder, weighed, and randomly assigned to groups receiving intraperitoneal injections of $.5 \mathrm{mg} / \mathrm{kg}$ or $1 \mathrm{mg} / \mathrm{kg}$ of epinephrine. Half of each of these groups received either $1.0 \mathrm{mg} / \mathrm{kg}$ or $2.5 \mathrm{mg} / \mathrm{kg}$ of scopolamine hydrobromide. All injections were $1 \mathrm{cc} / \mathrm{kg}$. Following the two injections, the birds were placed in a holding box for $15 \mathrm{~min}$. Testing was similar to habituation; the birds were taken to the test room, removed from the holding box, and placed in the test box from above. The experimenter immediately reached through the cloth front, grasped the bird, turned it on its side, and held it down for $15 \mathrm{sec}$. Duration of TI was timed from release until spontaneous righting occurred or $900 \mathrm{sec}$ had elapsed. If a bird failed to stay down at least $5 \mathrm{sec}$, inductions were continued until it did or until five inductions had been given. Birds failing to show TI of at least $5 \mathrm{sec}$ were given duration scores of zero.

\section{RESULTS AND DISCUSSION}

Mean duration of TI in seconds for each group is presented in Figure 1. As can be seen in the figure, the highest dosage of epinephrine dramatically increased TI duration for both scopolamine-treated groups $[F(1,36)=4.22, p<.05]$. Although the highest dosage of scopolamine reduced TI duration at both levels of 


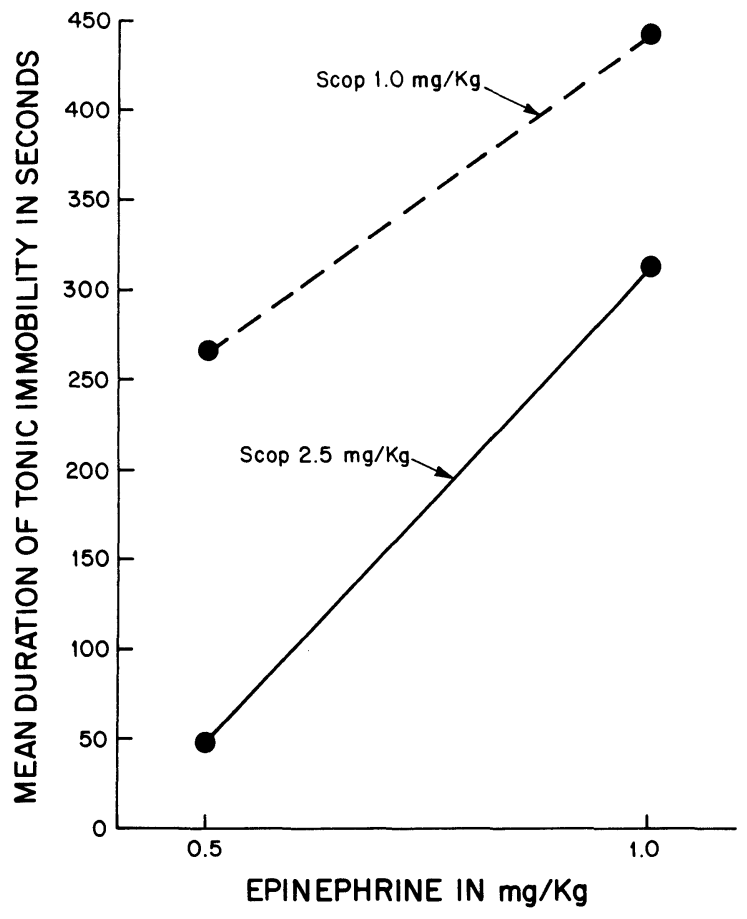

Figure 1. Mean duration of tonic immobility in seconds for groups at each level of epinephrine and scopolamine.

epinephrine, the effect did not reach conventional levels of significance $[F(1,36)=2.01, p<.20]$.

The mean number of trials to induce TI for the $.5-\mathrm{mg} / \mathrm{kg}$ epinephrine groups receiving 1.0 and $2.5 \mathrm{mg} / \mathrm{kg}$ of scopolamine were 1.9 and 2.3 , respectively. For the $1.0-\mathrm{mg} / \mathrm{kg}$ epinephrine groups, the means were 1.7 and 1.2 for the 1.0 and $2.5 \mathrm{mg} / \mathrm{kg}$ of scopolamine groups, respectively. Analysis of these data revealed that the highest dosage of epinephrine resulted in fewer trials to induce TI than did the lower dosage $[F(1,36)=3.42$, $\mathrm{p}<.05$ ]

Although Carlton's (1969) hypothesis was not strongly supported by the present experiment, the data are consistent with those of previous studies (Braud \& Ginsburg, 1973; Gagliardi \& Thompson, 1977; Thompson, 1977; Thompson et al., 1977). Previous experiments on TI in chickens with cholinergic blocking drugs have used nonhabituated birds. Habituation is used to reduce fear, and it has been hypothesized that one of the effects of anticholinergics is to reduce fear (Plotnik, Mollenauer, \& Snyder, 1974). Perhaps the habituation to handling and the TI induction procedure' had reduced fear to such an extent that no further reduction was possible. In this context it should be pointed out, however, that all but one bird in this experiment showed at least $5 \mathrm{sec}$ of TI.

It is possible that there are several processes involved in TI: one associated with the initiation of the response, another with its continuation, and a third with its termination. At least four transmitters have been shown to affect TI: serotonin (Wallnau \& Gallup, 1977), acetycholine (Thompson, 1977), epinephrine and norepinephrine (Braud \& Ginsburg, 1973; Thompson \& Joseph, 1978), and dopamine (Ettinger \& Thompson, 1978). However, no attempt has been made to show that a particular transmitter substance is associated with any one of these processes.

\section{REFERENCES}

Braud, W. G., \& Ginsburg, R. J. Effect of administration of adrenalin on immobility reaction in domestic fowl. Journal of Comparative and Physiological Psychology, 1973, 83, 124-127.

Carlton, P. L. Brain-acetylcholine and inhibition. In J. L. Tapp (Ed.), Reinforcement and behavior. New York: Academic Press, 1969.

EtTinger, R. H., \& Thompson, R. W. The role of dopaminergic systems in the mediation of tonic immobility (animal hypnosis) in chickens. Bulletin of the Psychonomic Society, 1978, 12, 301-302.

Gagliardi, G., \& Thompson, R. W. Cholinergic blockade and tonic immobility in chickens. Bulletin of the Psychonomic Society, 1977, 9, 343-345.

Gallup, G. G., JR. Animal hypnosis: Factual status of a fictional concept. Psychological Bulletin, 1974, 81, 836-853.

Manto, P. G. Blockade of epinephrine-induced decrement in activity by scopolamine. Psychonomic Science, 1967, 7, 203-204.

Plotnik, R., Mollenauer, S., \& Snyder, E. Fear reduction in the rat following central cholinergic blockade. Journal of Comparative and Physiological Psychology, 1974, 86, 1074-1082.

Tном PSon, R. W. A central cholinergic inhibition system as a basis for tonic immobility in chickens. Psychological Record, 1977, 27, 109-121.

Thompson, R. W., \& Jose PH, S. The effect of norepinephrine on tonic immobility in chickens. Bulletin of the Psychonomic Society, 1978, 12, 123-124.

Thompson, R. W., Scuderi, R., \& Boren, J. The effect of epinephrine on tonic immobility (animal hypnosis) in chickens. Bulletin of the Psychonomic Society, 1977, 9, 409-410.

Wallnau, L. B., \& Gallup, G. G., JR. A serotonergic, midbrainRaphé model of tonic immobility. Biobehavioral Reviews, 1977, 1, 35-43.

(Received for publication October 22, 1979.) 